\title{
Case Report: Guitarist's cramp as the initial manifestation of dopa-responsive dystonia with a novel heterozygous GCH1
} mutation [version 1; peer review: 2 approved, 1 approved with reservations]

\author{
Takafumi Hasegawa (D1), Tatsuhiko Hosaka1, Ryuhei Harada(iD), Ichiro Kawahata2, \\ Kyoko Hoshino ${ }^{3}$, Naoto Sugeno ${ }^{1}$, Akio Kikuchi ${ }^{1}$, Masashi Aoki ${ }^{1}$ \\ ${ }^{1}$ Division of Neurology, Department of Neuroscience and Sensory Organs, Tohoku University Graduate School of Medicine, Sendai, \\ Miyagi, 980-8574, Japan \\ 2Department of Pharmacotherapy, Graduate School of Pharmaceutical Sciences, Tohoku University, Sendai, Miyagi, 980-8578, Japan \\ ${ }^{3}$ Department of Pediatric Neurology, Segawa Memorial Neurological Clinic for Children, Kanda, Tokyo, 101-0062, Japan
}

V1 First published: 07 May 2021, 10:361

https://doi.org/10.12688/f1000research.51433.1

Latest published: 07 May 2021, 10:361

https://doi.org/10.12688/f1000research.51433.1

\section{Abstract}

Dopa-responsive dystonia (DRD), also known as Segawa syndrome, is a phenotypically and genetically heterogeneous group of neurological disorders that typically presents as early-onset lower limb dystonia with diurnal fluctuation, and exhibits a marked, persistent response to levodopa. Heterozygous loss-of-function mutations in the guanosine triphosphate cyclohydrolase 1 (GCH1) are the most common cause of DRD. In addition to the classic form of the disease, there have been a number of studies addressing atypical clinical features of $\mathrm{GCH} 1$ related DRD with variable age of onset. This report describes a 37year-old Japanese male patient with a 10-year history of focal upper limb dystonia that initially emerged as task-specific, guitarist's cramp. The dystonic symptoms responded very well to levodopa treatment, and genetic analysis identified a novel heterozygous mutation in the $\mathrm{C}$-terminal catalytic domain of GCH1. Insufficient recognition of this treatable condition often leads to misdiagnosis, which causes delays in the patient receiving adequate dopamine replenishing therapy. A diagnostic trial with levodopa should be considered in all patients with relatively young-onset dystonia, whether they have classic features of DRD or not.

\section{Keywords}

Guitarist's cramp, dystonia, task-specific, dopa-responsive, dopamine, Segawa syndrome, GCH1, DYT5a

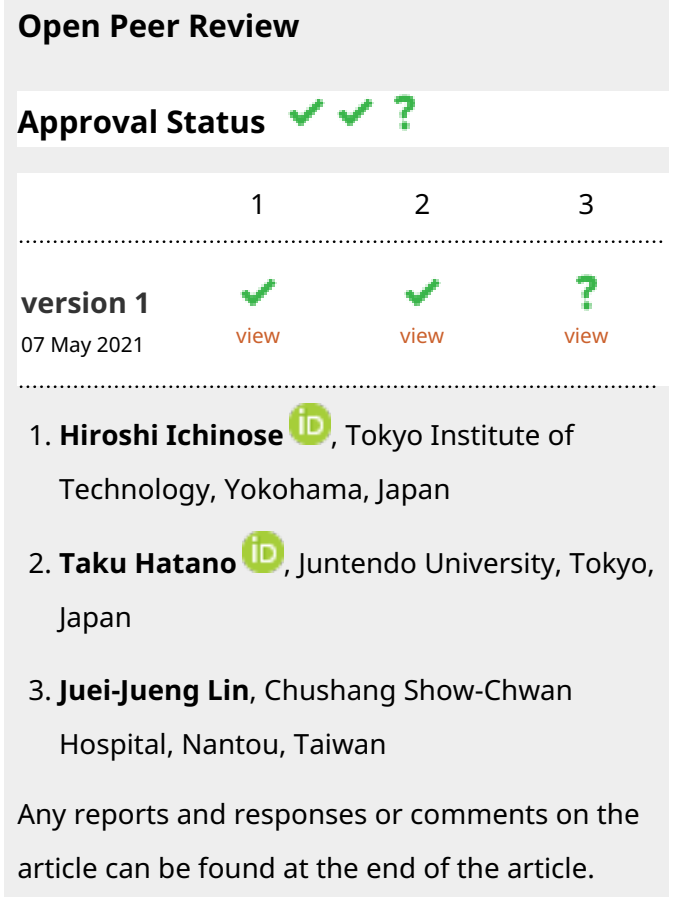

article can be found at the end of the article. 
Corresponding author: Takafumi Hasegawa (thasegawa@med.tohoku.ac.jp)

Author roles: Hasegawa T: Conceptualization, Formal Analysis, Funding Acquisition, Investigation, Methodology, Project Administration, Resources, Validation, Visualization, Writing - Original Draft Preparation; Hosaka T: Investigation, Resources; Harada R: Investigation, Resources; Kawahata I: Funding Acquisition, Investigation, Methodology; Hoshino K: Supervision; Sugeno N: Investigation, Resources; Kikuchi A: Investigation, Resources; Aoki M: Supervision

Competing interests: No competing interests were disclosed.

Grant information: This work was supported in part by a Grant-in-Aid for Scientific Research (C) from the Ministry of Education, Culture, Sports, Science and Technology (assigned to Takafumi Hasegawa; grant number 20K07896). The research was also supported by Kawano Masanori Memorial Foundation for Promotion of Pediatrics (assigned to Ichiro Kawahata).

Copyright: $\odot 2021$ Hasegawa T et al. This is an open access article distributed under the terms of the Creative Commons Attribution License, which permits unrestricted use, distribution, and reproduction in any medium, provided the original work is properly cited.

How to cite this article: Hasegawa T, Hosaka T, Harada R et al. Case Report: Guitarist's cramp as the initial manifestation of doparesponsive dystonia with a novel heterozygous GCH1 mutation [version 1; peer review: 2 approved, 1 approved with reservations] F1000Research 2021, 10:361 https://doi.org/10.12688/f1000research.51433.1

First published: 07 May 2021, 10:361 https://doi.org/10.12688/f1000research.51433.1 


\section{Introduction}

Dopa-responsive dystonia (DRD, Segawa syndrome) is a rare movement disorder typically characterized by childhood-onset walking difficulties due to lower limb dystonia, diurnal fluctuation, and dramatic, sustained response to relatively low-dose levodopa treatment ${ }^{1}$. Striatal dopamine deficiency due to lossof-function mutations in the guanosine triphosphate cyclohydrolase 1 (GCH1, EC 3.5.4.16) is the most common etiology in the autosomal dominant form of DRD (DYT5a, OMIM 128230), in which incomplete penetrance and variable phenotype are observed $^{2}$. Owing to its diverse clinical presentations and poor recognition by general practitioners, DRD is under-reported and may be mistaken for other conditions such as cerebral palsy or psychogenic movement disorder. In this report, an unusual, adult case of DRD/DYT5a initially presenting as guitarist's dystonia is described.

\section{Case report}

The 37-year-old, right-handed Japanese man with a professional career as a guitar player, was referred to our hospital for the reassessment of upper limb dystonia. Upon assessment, no family history of neurological disorders was reported, and he did not use any regular medication before onset. At the age of 27 years, he began to spend most of his time practicing guitar and three months later, he felt difficulty in picking a pick due to excessive wrist extension and intermittent, tremulous finger movement in the right hand. At the age of 29 years, he was diagnosed with having guitarist's cramp, for which the oral administration of clonazepam $(1.5 \mathrm{mg} /$ day $)$ and trihexyphenidyl $(6 \mathrm{mg} / \mathrm{day})$ were prescribed. This treatment proved to be ineffective. After switching from guitar to piano, these strange movements transiently disappeared but later reappeared. Meanwhile, the task-specificity of hand dystonia was gradually lost, and the disabling hand dystonia was induced by other daily activities including opening/closing a screw cap bottle and the brushing of his teeth. After fiveyears from the onset, he had considerable difficulty in playing instruments, and finally, he decided to end his musical activities.
During consultation, neurological examination of cranial nerves, motor function, coordination, sensory function, and autonomic function showed unremarkable results. This was with the exception of action-induced dystonic posturing of the right upper limb with excessive wrist extension and hyperextension of the fingers, though these findings only became prominent during voluntary, skilled movement (Video S1, Extended data ${ }^{3}$ ). Neither sensory trick nor diurnal variation was observed. Other abnormalities, including cognitive dysfunction, parkinsonism, pyramidal signs, and cerebellar ataxia, were not detected. Workup including electrolytes, renal function tests, complete blood count, liver function tests and urinalysis were unremarkable. In addition, the levels of serum copper and ceruloplasmin were normal. Cranial magnetic resonance imaging and dopamine transporter (DAT) imaging

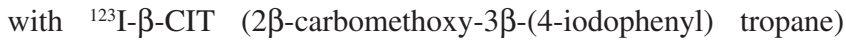
single-photon emission computed tomography were normal (Figure 1). The diagnosis of DRD was suspected since the oral administration of levodopa (300 $\mathrm{mg}$ per day) showed dramatic, sustained improvement of the dystonic symptoms on the following day (Video S2, Extended $\operatorname{data}^{3}$ ), and cerebrospinal fluid analyses revealed a significant decrease in homovanillic acid (22.6 ng/ml, normal range: 41.6-178 ng/ml), 5-hydroxyindoleacetic acid $(9.1 \mathrm{ng} / \mathrm{ml}$, normal range: $20.0-96.0 \mathrm{ng} / \mathrm{ml})$, and total neopterin $(2.0 \mathrm{pmol} / \mathrm{ml}$, normal range: $9.0-20.0 \mathrm{pmol} / \mathrm{ml})$ levels ${ }^{4}$. The clinical suspicion of DRD was further strengthened by exome analysis and Sanger sequencing showing a novel heterozygous mutation c. $542 \mathrm{~T}>\mathrm{G}$ (p. Val181Gly) in the first amino acid of exon 5 in GCH1 gene (Figure 2A). The first Val in the 5th exon was located in the enzymatic core of $\mathrm{GCH} 1$ at the $\mathrm{C}$-terminus ${ }^{5}$, and is highly conserved across species (Figure 2B). This amino acid substitution was predicted to be pathogenic using the in silico analysis tools, SIFT and PolyPhen-2. In the half-year followup, the patient's dystonic symptom was well-controlled by the levodopa therapy without any adverse side effects.

\section{Discussion}

In most cases of adult-onset focal limb dystonia, the exact, underlying etiology remains unclear, but in some cases, dystonia
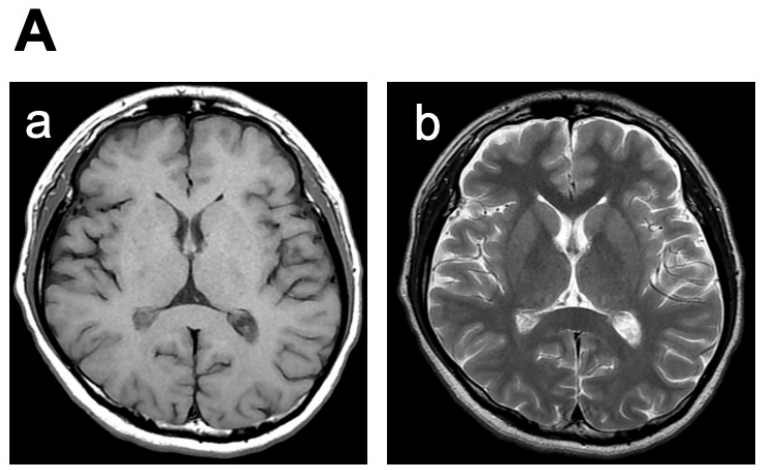

B

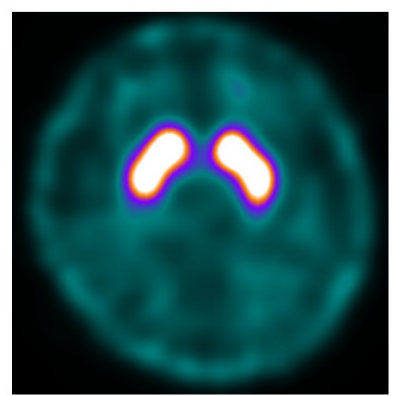

Figure 1. A: Cranial magnetic resonance imaging shows no abnormality in (a) $T 1$ and (b) T2 axial sequences. B: Transverse dopamine

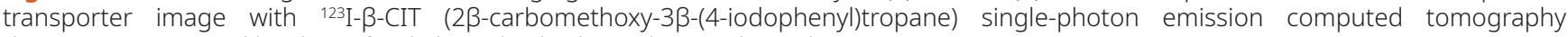
demonstrates normal binding of radioligand in both caudate nuclei and putamina. 


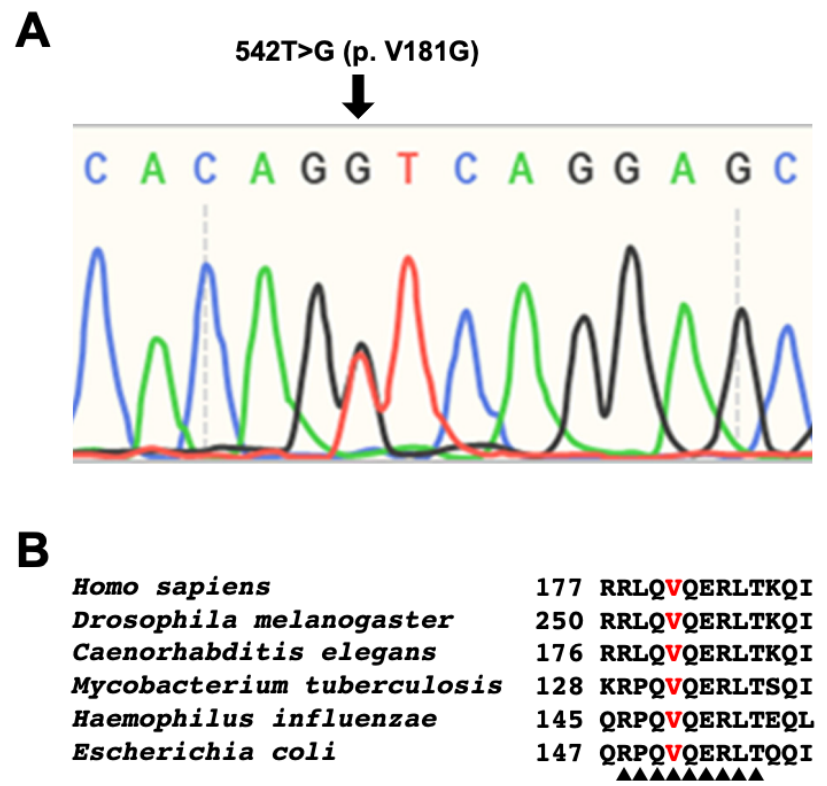

Figure 2. A: Sanger sequencing chromatogram which shows a novel heterozygous mutation c. $542 T>G$ ( $p$. Val181Gly) in the first amino acid of exon 5 in the GCH1 gene (black arrow). B: Amino acid sequence alignment of the GCH1. Note that the first Val in exon 5 (highlighted in red) is highly conserved across species. Residues involved in catalysis are highlighted with black triangles

occurs due to specific biochemical defects and genetic alterations ${ }^{6}$. A good example is the DRD caused by genetic defects in dopamine biosynthesis. Deficiency of $\mathrm{GCH} 1$, a rate-limiting enzyme in the biosynthetic pathway of tetrahydrobiopterin, is the most common and well-characterized condition that manifests as $\mathrm{DRD}^{7}$. In contrast to the childhood-onset GCH1-related DRD, adult cases often present parkinsonism followed by dystonia, and the movement problems progress slowly without diurnal variation $^{8,9}$. Furthermore, a number of studies describing atypical or incompatible features of GCH1 deficient-DRD with variable age of onset exist ${ }^{2}$. Theoretically, DRD is considered to be a neurotransmitter disorder that is not accompanied by the nigrostriatal degeneration; however, some patients with adult-onset dystonia-parkinsonism or Parkinson's disease without any dystonic feature carrying GCH1 mutation have been known to show abnormal DAT imaging ${ }^{2}$.

The most conspicuous feature in this patient's case is that the dystonic movement which started to present as a guitarist's cramp. Although infrequent, a few reports of DRD/DYT5a presenting task-specific dystonia in the upper limb have been presented $^{10,11}$. Among them, the most common phenotype was writer's cramp, which became obvious during the disease progression. Conversely, there was only one case report which presented adult-onset guitarist's cramp in the family carrying GCH1 truncating mutation (p. Arg216stop) ${ }^{12}$. A genotype-phenotype correlation was unlikely, because even among members of the same family with the same mutation, the movement symptoms were different. While the pathophysiology of task-specific or occupational dystonia still remains elusive, overtraining and genetic predisposition may contribute to the expression of dystonic symptoms. Indeed, about $20 \%$ of patients with musician's dystonia have a family history of the disorder, and a genomewide association study demonstrated a possible link between musician's dystonia and the intronic variant in the arylsulfatase G gene ${ }^{13}$. Furthermore, patients with DYT1 and DYT11 dystonia rarely have writer's cramp as the cardinal symptom ${ }^{14,15}$. Although we did not conduct personality and behavioral assessment of the patient, specific personality traits including susceptibility to anxiety and stress, or perfectionism may also increase the risk of developing dystonia ${ }^{16}$.

In conclusion, we reported a case of a 37-year-old male who was diagnosed with DRD/DYT5a, which was confirmed through genetic sequencing. The patient presented focal upper limb dystonia which first emerged as task-specific, guitarist's cramp. The clinical heterogeneity of DRD often makes diagnosis difficult and leads to therapeutic delay. Our experience further underscores the broad clinical presentations of DRD as well as advocating for the diagnostic value of trying levodopa and genetic testing in dystonia.

\section{Data availability}

Underlying data

All data underlying the results are available as part of the article and no additional source data are required.

\section{Extended data}

Dryad: Dopa-responsive dystonia patient response before and after levodopa treatment. https://doi.org/10.5061/dryad.pzgmsbckd³. 
This project contains the following extended data:

- Video S1 (.MOV video of the neurological assessment on admission. Dystonic posturing of the right upper limb with excessive wrist extension and hyperextension of the fingers are seen during the opening of a screw cap bottle. No parkinsonism, pyramidal signs or cerebellar ataxia are observed)

- Video S2 (.MOV video taken on the following day after the oral administration of $300 \mathrm{mg}$ per day of levodopa. The task-specific dystonia in the right upper limb is dramatically improved).

Data are available under the terms of the Creative Commons Zero "No rights reserved" data waiver (CCO 1.0 Public domain dedication).

\section{Consent}

Written informed consent for publication of the clinical details, diagnostic images and videos was obtained from the patient.

\section{Author contributions}

Conceptualization: THA

Formal Analysis: THA

Funding Acquisition: THA, IK

Investigation: THA, THO, RH, IK, NS, AK

Methodology: THA, IK

Project Administration: THA

Resources: THA, THO, RH, NS, AK,

Supervision: KH, MA

Validation: THA

Visualization: THA

Writing - Original Draft Preparation: THA
1. Segawa M, Hosaka A, Miyagawa F, et al.: Hereditary progressive dystonia with marked diurnal fluctuation. Adv Neurol. 1976; 14: 215-233. PubMed Abstract

2. Wijemanne $S$, Jankovic J: Dopa-responsive dystonia--clinical and genetic heterogeneity. Nat Rev Neurol. 2015; 11(7): 414-424. PubMed Abstract | Publisher Full Text

3. Hasegawa T: Dopa-responsive dystonia patient response before and after levodopa treatment. Dryad. Dataset, 2021. http://www.doi.org/10.5061/dryad.pzgmsbckd

4. Blau N, Bonafé L, Thöny B: Tetrahydrobiopterin deficiencies without hyperphenylalaninemia: diagnosis and genetics of dopa-responsive dystonia and sepiapterin reductase deficiency. Mol Genet Metab. 2001; 74(1-2): $172-185$.

PubMed Abstract | Publisher Full Text

5. Maita N, Hatakeyama K, Okada K, et al: Structural basis of biopterin-induced inhibition of GTP cyclohydrolase I by GFRP, its feedback regulatory protein. J Biol Chem. 2004; 279(49): 51534-51540. PubMed Abstract | Publisher Full Text

6. Albanese $\mathrm{A}, \mathrm{Di}$ Giovanni M, Lalli S: Dystonia: diagnosis and management. Eur J Neurol. 2019; 26(1): 5-17.

PubMed Abstract | Publisher Full Text

7. Ichinose $\mathrm{H}$, Ohye $\mathrm{T}$, Takahashi $\mathrm{E}$, et al:: Hereditary progressive dystonia with marked diurnal fluctuation caused by mutations in the GTP cyclohydrolase I gene. Nat Genet. 1994; 8(3): 236-242. PubMed Abstract | Publisher Full Text

8. Kikuchi A, Takeda A, Fujihara K, et al.: Arg(184)His mutant GTP cyclohydrolase I, causing recessive hyperphenylalaninemia, is responsible for doparesponsive dystonia with parkinsonism: a case report. Mov Disord. 2004;
19(5): 590-593. PubMed Abstract | Publisher Full Text

9. Weng YC, Wang CC, Wu YR: Atypical presentation of dopa-responsive dystonia in Taiwan. Brain Behav. 2018; 8(2): e00906. PubMed Abstract | Publisher Full Text | Free Full Text

10. Trender-Gerhard I, Sweeney MG, Schwingenschuh P, et al: Autosomaldominant GTPCH1-deficient DRD: clinical characteristics and long-term outcome of 34 patients. J Neurol Neurosurg Psychiatry. 2009; 80(8): 839-845. PubMed Abstract | Publisher Full Text

11. Tassin J, Dürr A, Bonnet AM, et al.: Levodopa-responsive dystonia. GTP cyclohydrolase I or parkin mutations? Brain. 2000; 123(Pt 6): 1112-1121. PubMed Abstract | Publisher Full Text

12. Bandmann $O$, Valente EM, Holmans $P$, et al:: Dopa-responsive dystonia: a clinical and molecular genetic study. Ann Neurol. 1998; 44(4): 649-656. PubMed Abstract | Publisher Full Text

13. Lohmann K, Schmidt A, Schillert A, et al.: Genome-wide association study in musician's dystonia: a risk variant at the arylsulfatase G locus? Mov Disord. 2014; 29(7): 921-927.

PubMed Abstract | Publisher Full Text

14. Gerrits MCF, Foncke EMJ, Koelman JHTM, et al.: Pediatric writer's cramp in myoclonus-dystonia: maternal imprinting hides positive family history. Eur J Paediatr Neurol. 2009; 13(2): 178-180. PubMed Abstract | Publisher Full Text

15. Gasser T: Inherited myoclonus-dystonia syndrome. Adv Neurol. 1998; 78: 325-334. PubMed Abstract

16. Tomić A, Petrović I, Pešić $D$, et al.: Is there a specific psychiatric background or personality profile in functional dystonia? J Psychosom Res. 2017; 97: 58-62. PubMed Abstract | Publisher Full Text 


\section{Open Peer Review}

\section{Current Peer Review Status:}

\section{Version 1}

Reviewer Report 17 August 2021

https://doi.org/10.5256/f1000research.54602.r90521

(C) 2021 Lin J. This is an open access peer review report distributed under the terms of the Creative Commons Attribution License, which permits unrestricted use, distribution, and reproduction in any medium, provided the original work is properly cited.

\section{Juei-Jueng Lin \\ Department of Neurology, Chushang Show-Chwan Hospital, Nantou, Taiwan}

Hasegawa T et al. report a young adult man with a 10-year history of upper limb dystonia that mimicked as task-specific dystonia. His dystonia responded well to Levodopa treatment and his genetic study revealed a novel heterozygous mutation of GCH1 gene. Therefore, they conclude task-specific dystonia can also be one phenotype of Segawa syndrome or dopa-responsive dystonia (DRD). Meanwhile, a series of neuroimaging studies of this case including CT, MRI and SPECT of the brain were all negative results.

I am interested in this case, but I have three major comments on this paper:

1. The authors emphasized that the patient presented guitarist's cramp in his early stage of disease, three months later after an intensive practice of guitar. Meanwhile, they also described the dystonia can also appear in playing other instruments and in some daily activity. This manifestation is different from the disease course of idiopathic task-specific dystonia. The authors should discuss the differences between idiopathic task-specific dystonia and genetic related task-specific dystonia.

2. The patient responded well to treatment with levodopa and was subsequently diagnosed to be DRD, but did not have a family history. The genetic testing for $\mathrm{GCH} 1$ gene revealed a novel heterozygous mutation of $\mathrm{c}$. $542 \mathrm{~T}>\mathrm{G}$. However, the paper does not mention genetic analysis for $\mathrm{GCH} 1$ of his parent or siblings. Therefore, the authors should provide the genetic testing of $\mathrm{GCH} 1$ of other families to confirm genetic basis of their reported patient, In addition, they also can discuss the intrafamilial variability of photype in DRD family.

3. The authors also reported a normal presynaptic nigrostriatal dopamine function by a normal SPECT study in their DRD case. There have been reports in literature with an abnormal presynaptic nigrostriatal dopamine function in DRD patient presented with either dystonia or Parkinsonism. The author should discuss the relationship of presynaptic dopamine function in patients with DRD presented with variably clinical phenotypes.

\section{Is the background of the case's history and progression described in sufficient detail?}


Partly

Are enough details provided of any physical examination and diagnostic tests, treatment given and outcomes?

Partly

Is sufficient discussion included of the importance of the findings and their relevance to future understanding of disease processes, diagnosis or treatment?

Partly

Is the case presented with sufficient detail to be useful for other practitioners?

Partly

Competing Interests: No competing interests were disclosed.

Reviewer Expertise: Parkinson's disease and related disorders

I confirm that I have read this submission and believe that I have an appropriate level of expertise to confirm that it is of an acceptable scientific standard, however I have significant reservations, as outlined above.

Reviewer Report 09 August 2021

https://doi.org/10.5256/f1000research.54602.r90523

(C) 2021 Hatano T. This is an open access peer review report distributed under the terms of the Creative Commons Attribution License, which permits unrestricted use, distribution, and reproduction in any medium, provided the original work is properly cited.

\section{Taku Hatano}

Department of Neurology, Faculty of Medicine, Juntendo University, Tokyo, Japan

Hasegawa and colleagues reported the case with DYT5, who exhibited the focal dystonia mimicking musician's cramp. They described the patient's medical story and assessed the patient's state by appropriate examinations, including neurological examination, cranial MRI, DAT scan, and genetic analysis. They also mentioned the important learning points. Thus, I am interested in this paper.

But I have a comment on this paper.

\section{Major point:}

The authors pronounced that in the early stage, the patient exhibited the mimicking guitarist's cramp, but his dystonia emerged in not only task-specific but also usual situations. This finding is different from idiopathic task-specific dystonia in the disease course. The authors should discuss the difference between genetic-related and idiopathic task-specific dystonia. 
Is the background of the case's history and progression described in sufficient detail? Yes

Are enough details provided of any physical examination and diagnostic tests, treatment given and outcomes?

Yes

Is sufficient discussion included of the importance of the findings and their relevance to future understanding of disease processes, diagnosis or treatment?

Yes

Is the case presented with sufficient detail to be useful for other practitioners?

Yes

Competing Interests: No competing interests were disclosed.

Reviewer Expertise: Parkinson's disease, Movement disorders

I confirm that I have read this submission and believe that I have an appropriate level of expertise to confirm that it is of an acceptable scientific standard.

Reviewer Report 08 June 2021

https://doi.org/10.5256/f1000research.54602.r84972

(C) 2021 Ichinose $\mathbf{H}$. This is an open access peer review report distributed under the terms of the Creative Commons Attribution License, which permits unrestricted use, distribution, and reproduction in any medium, provided the original work is properly cited.

\section{Hiroshi Ichinose}

School of Life Science and Technology, Tokyo Institute of Technology, Yokohama, Japan

The authors described an adult male case of DRD/DYT5a who initially developed focal upper limb dystonia and diagnosed as guitarist's dystonia, and found that the dystonic symptoms responded very well to levodopa treatment. They propose that a diagnostic trial with levodopa should be considered in all patients with relatively young-onset dystonia regardless of whether they have typical features of DRD or not.

This paper is worthwhile publishing to report that adult-onset focal limb dystonia can be presented in patients with DRD/DYT5a, suggesting a broad clinical presentation of DRD/DYT5a.

The reviewer would like to ask for the following minor revision to the manuscript;

1. The authors should discuss the benefits and possible adverse effects of levodopa treatment for the patients with dystonia, whereas the authors propose the diagnostic value of levodopa treatment.

2. The biochemical analysis of HVA and neopterin in the CSF is beneficial for a differential 
diagnosis of DRD/DYT5a from other types of dystonia/parkinsonism. It should be discussed clearly in the text.

Is the background of the case's history and progression described in sufficient detail? Yes

Are enough details provided of any physical examination and diagnostic tests, treatment given and outcomes?

Yes

Is sufficient discussion included of the importance of the findings and their relevance to future understanding of disease processes, diagnosis or treatment?

Yes

Is the case presented with sufficient detail to be useful for other practitioners?

Yes

Competing Interests: No competing interests were disclosed.

Reviewer Expertise: Biochemistry

I confirm that I have read this submission and believe that I have an appropriate level of expertise to confirm that it is of an acceptable scientific standard.

The benefits of publishing with F1000Research:

- Your article is published within days, with no editorial bias

- You can publish traditional articles, null/negative results, case reports, data notes and more

- The peer review process is transparent and collaborative

- Your article is indexed in PubMed after passing peer review

- Dedicated customer support at every stage

For pre-submission enquiries, contact research@f1000.com 